\title{
PRICE ADJUSTMENT COSTS, ANTICIPATED INFLATION, AND OUTPUT*
}

\author{
TIMUR KURAN
}

\section{INTRODUCTION}

Even when inflation is perfectly predictable, a firm for whick price adjustment is costly will keep its nominal price unchanged for extended periods. At least part of the time, therefore, the firm's real price will diverge from the price that maximizes its instantaneous profits. In the interval between adjustments, the firm's real price will start out above the profit-maximizing price and eventually fall below this as the general price level rises. An implication is that the firm's actual output will fall short of the profit-maximizing level during the initial stages of an adjustment interval and exceed it during the later stages.

At this level of generality it is not clear whether the gains in the firm's output or the losses will be dominant. This issue is explored here with the help of a model used in another paper [Kuran, 1983] to study the effects of inflation on a price-setting firm's adjustment pattern; a brief outline of this model is presented in Section II. The earlier analysis reveals that when adjustment costs force the firm to choose a single nominal price for two consecutive periods in which the price level is different, the price it selects may be biased toward the optimal nominal price in one of the two periods. It does not, however, discuss the implications of a firm's pricing policy for its output levels. This task is performed in Section III, which shows that the firm's total output may be either an increasing or a decreasing function of the inflation rate, depending on the characteristics of its demand function. ${ }^{1}$

1. It may appear that the question just outlined can be answered using Proposition 2 in my earlier paper, which deals with bias in pricing. But this is not so, because that notion of bias involves the geometric mean, whereas the arithmetic sum, which varies linearly with the arithmetic mean, is relevant here (see Section III). From the direction of pricing bias one can in some cases infer how inflation affects the geometric average of output, but at any rate this information is not of interest in the present context.

*I am grateful to Kenneth Arrow, Paul Evans, David Starrett, Wayne Shafer, Andrew Abel, and the anonymous referees of this Journal for valuable criticisms and suggestions on earlier drafts. 
As with the earlier findings, this result stems from the fact that a firm's profit function is generally asymmetric in price, in the sense that the opportunity loss from pricing below the optimal level is different than the corresponding loss from pricing above it by a proportionally equivalent amount. In no way does the result depend on money illusion. It holds even if all relevant agents base their decisions on real variables.

The result is significant because it is often claimed in current economic discussions that anticipated nominal changes do not have real effects. Implicit in this claim is the assumption that price adjustment is costless: inflation leaves relative prices, and hence firms' outputs, unaffected because in the absence of adjustment costs all prices adjust instantaneously. This assumption is not, however, based on sound microeconomic principles. It may not be rational for firms to change their prices on, say, a day-today basis, even under double- or triple-digit inflation. This is so because a nominal price change can be costly to a firm even when no real change is involved. Selecting a nominal price and disseminating price information to dealers, distributors, and potential customers both require time and other resources. Another reason why the firm might find adjustments costly is that buyers prefer nominal price stability-a feature rooted not in money illusion, but in the biological fact that people's memories and informationprocessing capabilities are bounded. ${ }^{2}$ Once one grants that such adjustment costs exist, it becomes unreasonable to assert that anticipated inflation can have no real effects. Since inflation will affect the outputs of individual firms, one cannot rule out the possibility that it also affects aggregate output and employment. Some tentative thoughts on the macroeconomic implications of the analysis are offered in Section IV.

The observation that anticipated inflation can have real effects is not, of course, novel in itself. Phelps and Taylor [1977] have shown that inflation affects output if prices cannot respond to current shocks; unfortunately, however, their model does not incorporate the decision process that leads to price stickiness. Sheshinski and Weiss [1979] have established that in the presence of lump-sum adjustment costs inflation may cause firms to reduce their employment of fixed factors. And Blanchard [1983] has demonstrated that if the pricing policies of firms that are vertically

2. For detailed discussions of these and other price adjustment costs, see Tucker [1938], Alchian [1970], Okun [1981, Ch. 4], and Gordon [1981]. 
linked in production are asynchronized, real effects arise because the prices of primary inputs get transmitted to final output prices over several periods. The novelty of this paper lies in its emphasis on asymmetries in the firm's profit function.

\section{THE MODEL}

Consider a monopolistic profit-maximizing firm with a twoperiod planning horizon. In period 1 the firm's inverse demand function is

$$
p_{1}=p\left(x_{1}\right),
$$

where $p_{1}$ denotes nominal price in period 1 , and $p(\cdot)$ is a downward-sloping function. The general price level is 1 in this period, which implies that the firm's real price equals its nominal price. In period 2 the firm's inverse demand function becomes

$$
p_{2}=\mu p\left(x_{2} / \theta\right), \quad 0 \leqslant \theta<\infty, \quad 0<\mu<\infty,
$$

where $\theta$ and $\mu$ are proportional indexes, known with certainty, of changes in the firm's market size and price level, respectively. Values of $\mu$ above 1 signify inflation and those below 1 deflation. Note that equiproportionate changes in $\mu$ and $p_{2}$ would leave demand unaffected.

The parameter $\theta$ captures shifts in the firm's demand function caused by real forces such as technological discoveries, changes in people's tastes, and population growth. The parameter $\mu$, on the other hand, provides a measure of pure inflation-the type of inflation, that is, entailed in the addition of a zero to all monetary assets in the economy.

The firm's product is perishable, and since rationing of customers is harmful to the firm's reputation, this is not a viable policy option. Real marginal cost $c$ is constant. In nominal terms, therefore, marginal cost is $c$ in period 1 and $c \mu$ in period 2. Assuming that all factor costs are effectively indexed makes it possible to focus on the consequences of price adjustment. In reality the prices of some inputs are adjusted as infrequently as many final product prices because the manufacturers of inputs also incur price adjustment costs.

At the beginning of period 1 the firm sets out to maximize the present discounted value of its real profits:

$$
\Pi\left(x_{1}, x_{2}\right)=x_{1}\left[p_{1}-c\right]+\rho \mu^{-1} x_{2}\left[p_{2}-c \mu\right],
$$


where $\rho$ is the real discount factor. If price adjustment is costly, it will compare its maximum profits, net of any adjustment costs, under two alternatives: charging different nominal prices in the two periods and charging the same nominal price. Let the prices under the former alternative be $p_{1}^{* *}$ and $p_{2}^{* *}$, and the outputs, $x_{1}^{* *}$ and $x_{2}^{* *}$. It can easily be shown that $p_{2}^{* *}=p_{1}^{* *} \mu$ and that $x_{2}^{* *}=x_{1}^{* *} \theta$.

The latter alternative entails maximizing (3) subject to (1), (2), and

$$
p_{1}=p_{2} \text {. }
$$

The optimal price under this alternative will be denoted by $p^{*}$, and the corresponding outputs by $x_{1}^{*}$ and $x_{2}^{*}$. These outputs are the solutions of the first-order conditions:

$$
\begin{aligned}
\mu H_{1}+\rho \theta H_{2} & =0 ; \\
p\left(x_{1}^{*}\right)-\mu p\left(x_{2}^{*} / \theta\right) & =0,
\end{aligned}
$$

where

$$
H_{i}=\left[\left(\frac{x_{i}^{*}}{\theta^{i-1}}\right) p^{\prime}\left(\frac{x_{i}^{*}}{\theta^{i-1}}\right)+p\left(\frac{x_{i}^{*}}{\theta^{i-1}}\right)-c\right] / p^{\prime}\left(\frac{x_{i}^{*}}{\theta^{i-1}}\right),
$$

for $i=1,2$.

One can demonstrate that

$$
x_{1}^{*} \lessgtr x_{1}^{* *} \text { and } x_{2}^{*} \gtreqless x_{2}^{* *} \text { according as } \mu \gtreqless 1 .
$$

The range of $\mu$ for which the firm chooses the one-price alternative is situated around 1 , and its boundaries depend on the nature of the adjustment costs, in particular on how these costs vary with inflation and the size of the adjustment. But neither the properties of the adjustment costs, nor the particular boundaries will concern us here ${ }^{3}$ All that matters from the standpoint of this paper is the existence of costs that generate some range of $\mu$ where the firm prefers the one-price alternative.

Before we move on, it is appropriate to provide a rationale for assuming that the length of the firm's planning horizon is fixed. There exist in many industries particular times of year when firms are accustomed to reconsider their prices. For in-

3. See Kuran [1983] for a formal derivation of this range for the case where the adjustment costs are lump sum. 
stance, mail-order outlets and some producers of intermediate goods customarily revise their prices at the time they issue their fall catalogs. Under moderate inflation, then, a particular firm must decide whether to revise its prices just every fall or every spring as well. The crucial point is that as the inflation rate rises, such a firm does not reduce its adjustment interval from 12 months to 11 , then 10 , and so on. ${ }^{4}$ Instead, it maintains a year-long interval until inflation reaches, say, 12 percent, and then abruptly switches to a six-month interval. In terms of this example we shall be studying how output changes as the inflation rate varies between 0 and 12 percent.

\section{TOTAL OUTPUT UNDER INFLATION}

We are interested here in comparing $\hat{x}^{*} \equiv x_{1}^{*}+x_{2}^{*}$ with $\hat{x}^{* *} \equiv x_{1}^{* *}+x_{2}^{* *}$. The comparison is meaningful in a number of contexts. Suppose, for example, that the length of each period is six months. Then, $\hat{x}^{*}$ is the firm's annual production-a magnitude of interest to national planners as well as suppliers of the firm's inputs.

Using (5a) and (5b), one can show ${ }^{5}$ that for $\mu>(<) 1$,

$$
\begin{aligned}
& \frac{\partial \hat{x}^{*}}{\partial \mu} \gtreqless(\lessgtr) \theta \text { according as } \\
& \mu\left(2+J_{1}\right)-\rho\left(2+J_{2}\right)+\left(H_{1}-\rho H_{2}\right) / p\left(x_{2}^{*} / \theta\right) \gtreqless 0,
\end{aligned}
$$

where

$$
J_{i}=\left[c-p\left(\frac{x_{i}^{*}}{\theta^{i-1}}\right)\right] p^{\prime \prime}\left(\frac{x_{i}^{*}}{\theta^{i-1}}\right) / p^{\prime}\left(\frac{x_{i}^{*}}{\theta^{i-1}}\right), \quad \text { for } i=1,2 .
$$

This result, together with (6), indicates that a change in the rate of inflation (or deflation) can cause the firm's total output to rise, to stay constant, or to fall. It is possible, fortunately, to be more precise than this for certain families of demand functions that are widely used in empirical and theoretical work. Two such families will be considered: nonincreasing-elasticity functions of the form,

4. A model where this is the case has been considered by Sheshinski and Weiss [1977, 1979].

5 . The solution involves three steps. First, one takes total derivatives of the first-order conditions with respect to $\mu$. Then one solves for $\partial x_{1}^{*} / \partial \mu$ and $\partial x_{2}^{*} / \partial \mu$; this step involves some tedious algebra, but many terms cancel out. Finally, one sums the resulting expressions. 


$$
p=k+(a / x)^{1 / b}, \quad k \geqslant 0, \quad a>0, \quad b>1 ;
$$

and concave increasing-elasticity functions of the form,

$$
p=\left(\alpha-x^{\gamma}\right) / \beta, \quad \alpha, \beta>0, \quad \gamma \geqslant 1 .
$$

As we shall see, for both families the relationship between $\hat{x}^{*}$ and $\mu$ can be specified unambiguously. For strictly convex increasingelasticity functions, on the other hand, the sign of the derivative depends in an analytically complex manner on parameter values.

It is useful to begin the analysis of nonincreasing-elasticity functions with the case where $\rho=1$ and $\theta=1$. In this case, as indicated in Figure Ia, $\hat{x}^{*}$ falls below $\hat{x}^{* *}$ under inflation, implying that the fall in first-period output exceeds the rise in second-period output. ${ }^{6}$ The reason is that the firm's profit function is downwardasymmetric in price, in the sense that the loss in any given period from charging a price below the monopoly price exceeds the loss from charging a price above it by a proportionally equivalent amount. To compensate for the downward asymmetry in its profit function, the firm charges a price not at the midpoint between the two monopoly prices, but closer to $p_{2}^{* *}$, and this causes its



Ia). Decreasing- and constantelasticity demand functions

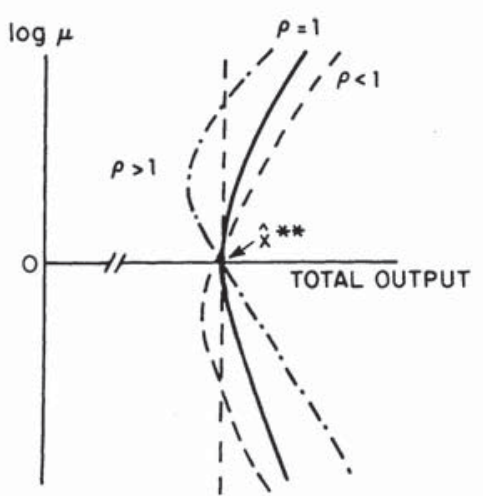

Ib). Concave increasing-elasticity demand functions

FIGURE I

Effect of Inflation on Total Output for Various Values of the Discount Factor

6. To prove this, compute $p, p^{\prime}$, and $p^{\prime \prime}$ at $x_{1}^{*}$ and $x_{2}^{*}$. Then plug these into (7), and set $\rho$ and $\theta$ equal to 1 . Simplifying, one finds that $\partial x^{*} / \partial \mu<0$ if and only if

$$
(1-\mu)(b-1)^{2} / b+(k-c)(b+1) a^{-1 / b}\left(x_{2}^{* 1 / b}-\mu x_{1}^{* 1 / b}\right)<0 .
$$

The validity of the latter inequality can be established by using ( $5 \mathrm{~b})$ and the fact that $k<c$ if the monopoly price is to be positive. 
average output to fall. ${ }^{7}$ Interestingly, total output falls under deflation, too. The explanation hinges again on the downward asymmetry of the profit function: because of this asymmetry the firm sets $p^{*}$ relatively closer to $p_{1}^{* *}$, the higher of the monopoly prices, thereby reducing total output.

What underlies the downward asymmetry in the profit function? One factor is that rationing is not feasible, so that the firm implicitly commits itself to supply whatever consumers demand at the announced price. Another factor is that production is instantaneous: the firm need not spend any resources until consumers have placed their orders. Together, these two factors ensure that when the firm's price is above the monopoly price, profits can go no lower than zero; and also, since marginal cost is positive, that when the firm's price is below the monopoly price, profits can become negative-in fact, infinitely negative as price tends to zero. This disparity would be mitigated if the price elasticity of demand were increasing in price. For then, consumers would be relatively less responsive to a fall in price than to a rise. With constant or decreasing elasticity, however, there exists no counteracting disparity between downward and upward displacements from the monopoly price, and the profit function exhibits downward asymmetry.

Returning to the analysis, we shall now explore the effect of variations in the discount factor, holding $\theta$ at 1 . An examination of (7) reveals that for $\mu>1$ reducing $\rho$ below 1 makes $\partial \hat{x}^{*} / \partial \mu$ positive if $\mu$ is sufficiently close to 1 . The explanation is that lowering $\rho$ makes the discounted value of maximum profits greater in the first period than in the second. This means that the firstperiod monopoly price exerts a greater gravitational pull than that of the second period. Under inflation, therefore, $p^{*}$ is lower than in the case where $\rho=1$, implying that output is higher in both periods. Under deflation, in contrast, $p^{*}$ is higher, and output is lower. The effects of a fall in $\rho$ can be seen in Figure Ia, where the output-inflation curve rotates clockwise when $\rho$ falls below 1 , and counterclockwise when $\rho$ rises above 1 .

These results indicate that when the real interest rate is positive $(\rho<1)$, inflation can raise $\hat{x}^{*}$ above $\hat{x}^{* *}$. Indeed, as $\mu$ rises above $1, \hat{x}^{*}$ rises, reaches a maximum, and finally declines. On the other hand, when the interest rate is negative $(\rho>1)$, the firm's average output under the one-price policy is always below $\hat{x}^{* *}$ for $\mu>1$. In this case $\hat{x}^{*}$ rises above $\hat{x}^{* *}$ only under deflation. 
The cases where $\theta$ is different from 1 lend themselves to a similar analysis. Since $\hat{x}^{* *}$ is an increasing function of $\theta$, the inflation-output curve for any given $\rho$ shifts to the right as $\theta$ rises. But all the qualitative results presented for the case where $\theta=1$ continue to hold.

For concave increasing-elasticity demand functions the relationship between $\hat{x}^{*}$ and $\mu$ is depicted in Figure $\mathrm{Ib}$. The figure shows that when $\rho=1$ both inflation and deflation raise total output under a one-price policy. ${ }^{8}$ The contrast with the nonincreasing-elasticity case is striking: while $\hat{x}^{*}$ is maximized at $\mu=1$ in that case, here it is minimized at $\mu=1$. The reason the result is qualitatively different is that $p^{*}$, the firm's optimal nominal price under the one-price policy, is closer to the smaller of the two monopoly prices. This is so because the firm's profit function is upward- rather than downward-asymmetric.

The explanation for the upward asymmetry of the profit function hinges on the fact that the price elasticity of demand is increasing in price. This means that quantity is relatively more responsive to a given upward displacement from the optimal price than to a proportionally equivalent downward displacement. Under inflation, therefore, if the firm sets $p^{*}$ at the midpoint between $p_{1}^{* *}$ and $p_{2}^{* *}$, its profits fall more in period 1 than in period 2 . To compensate for this asymmetry, the firm sets $p^{*}$ closer to $p_{1}^{* *}$, the smaller of the two monopoly prices. In doing so, it causes total output to rise.

A change in the firm's discount factor has qualitatively the same impact on the firm's output-inflation curve as in the nonincreasing-elasticity case. For reasons already explained, a fall in $\rho$ causes the curve to rotate clockwise around $\hat{x}^{* *}$, while a rise causes the curve to rotate counterclockwise. But in this case these rotations have different implications than in the nonincreasingelasticity case. In the present case, when $\rho$ falls below 1 , it becomes possible for inflation to cause a loss in total output; likewise, when $\rho$ rises above 1 , it becomes possible for deflation to lower total output. In the former case, in contrast, a discount factor different from 1 makes possible a gain in total output.

For two particular demand functions that are commonly used

8. Making the appropriate substitutions into (7), one finds that $\partial \hat{x}^{*} / \partial \mu>0$ if and only if

$$
\begin{aligned}
\gamma^{-1}\left[(\mu-1)(1+\gamma)+(\alpha-\beta c)(\gamma-1)\left(\mu x_{1}^{*-\gamma}\right.\right. & \left.\left.-x_{2}^{*-\gamma}\right)\right] \\
& +\beta^{-1}(1+\gamma)\left(x_{2}^{* \gamma}-x_{1}^{* \gamma}\right)>0 .
\end{aligned}
$$

The latter inequality holds because output is positive only when $\alpha>\beta c$, and because $\mu x_{1}^{*-\gamma}>x_{2}^{*-\gamma}$ on account of the constraint $\mu p\left(x_{2}^{*}\right)=p\left(x_{1}^{*}\right)$. 


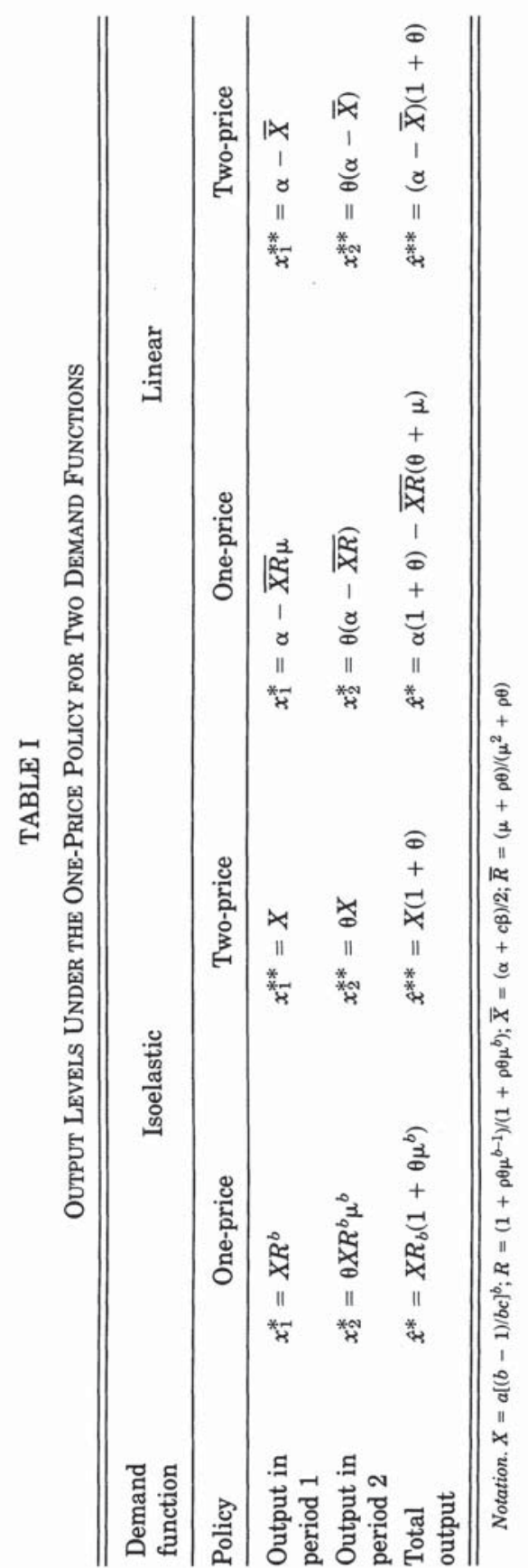


in empirical and analytical research, namely the isoelastic and the linear, the firm's optimal output levels are presented in Table I. The isoelastic function constitutes a special case of (8), where $k=0$. The linear function is obtained by setting $\gamma=1$ in (9).

For each of these cases, a few numerical examples of total output under the one-price policy relative to that under the twoprice policy are given in Table II. The table indicates that the impact of inflation on the firm's output is likely to be small, although not necessarily negligible. On the other hand, it is possible for the effect to be great. With the isoelastic function, for instance, the firm's total output falls 25.7 percent below the two-price level in the sixth case reported. One must be cautious, however, in interpreting the large entries in the table. Since large differences in total output correspond to large differences in total profits, as the table also indicates, the firm is likely to switch to the twoprice policy whenever the one-price policy would greatly reduce output. Only if the adjustment cost were extremely high would the firm pursue the one-price policy when this entails a large change in output relative to the two-price policy.

TABLE II

Comparison of Total Output and Total Profits under the ONE-PRice and Two-Price Policies

\begin{tabular}{|c|c|c|c|c|c|c|c|c|c|}
\hline \multicolumn{5}{|c|}{$\begin{array}{l}\text { Isoelastic demand function } \\
\qquad(\theta=1)\end{array}$} & \multicolumn{5}{|c|}{$\begin{array}{l}\text { Linear demand function } \\
(\theta=1, c=1, \alpha=20)\end{array}$} \\
\hline \multirow[b]{2}{*}{$\mu$} & \multirow[b]{2}{*}{$\rho$} & \multirow[b]{2}{*}{$b$} & \multicolumn{2}{|c|}{$\%$ difference } & \multirow[b]{2}{*}{$\mu$} & \multirow[b]{2}{*}{$\rho$} & \multirow[b]{2}{*}{$\beta$} & \multicolumn{2}{|c|}{$\%$ difference } \\
\hline & & & Output $^{\mathrm{a}}$ & Profits $^{\mathrm{b}}$ & & & & Output $^{\mathrm{a}}$ & Profits $^{\mathrm{b}}$ \\
\hline 1.05 & 1.0 & 5 & -0.6 & -0.6 & 1.05 & 1.0 & 1 & +0.1 & -0.1 \\
\hline 1.05 & 1.0 & 10 & -2.6 & -2.6 & 1.05 & 1.0 & 5 & +0.1 & -0.2 \\
\hline 1.05 & 1.0 & 20 & -9.6 & -9.6 & 1.05 & 1.0 & 10 & +0.2 & -0.5 \\
\hline 1.10 & 1.0 & 5 & -2.4 & -2.4 & 1.10 & 1.0 & 1 & +0.3 & -0.3 \\
\hline 1.10 & 1.0 & 10 & -8.9 & -8.9 & 1.10 & 1.0 & 5 & +0.4 & -0.6 \\
\hline 1.10 & 1.0 & 20 & -25.7 & -25.7 & 1.10 & 1.0 & 10 & +0.7 & -2.0 \\
\hline 1.05 & 0.95 & 5 & -0.3 & -0.6 & 1.05 & 0.95 & 1 & +0.1 & -0.1 \\
\hline 1.05 & 0.95 & 10 & -2.0 & -2.6 & 1.05 & 0.95 & 5 & +0.2 & -0.2 \\
\hline 1.05 & 0.95 & 20 & -8.7 & -9.8 & 1.05 & 0.95 & 10 & +0.4 & -0.5 \\
\hline
\end{tabular}




\section{CONCLUding REMARKS}

The foregoing discussion shows that when adjustment costs force a firm in an economy featuring inflation to change its nominal price at multiperiod intervals, the firm's output fluctuates over time around the instantaneously optimal level. Depending on the demand function, the firm's average output either rises or declines. While the net change in output is generally small for economically meaningful specifications, it is unlikely to be zero.

This result raises the question of how anticipated inflation affects aggregate output and employment in an economy where at least some firms incur price adjustment costs. Deriving these implications requires the aggregation of firms' factor demand and output supply schedules, an exercise that can be difficult when price-setting firms are involved. In a companion paper [Kuran, 1986] I have undertaken a preliminary investigation using the assumption that a large competitive sector with negligible adjustment costs exists alongside the price setters. The price setters incur significant adjustment costs, and all have two-period planning horizons. However, some have linear demand schedules, while the rest have isoelastic schedules. Within each category the firms come in pairs that are identical, except that their planning horizons are asynchronized. In particular, one firm adjusts its price in odd-numbered periods, the other in even-numbered periods. The crux of the model is that as relative prices change because of the price setters' adjustment policies, consumer expenditure is diverted from the price setters to the competitive sector, or vice versa.

Simulations of this model performed for meaningful demand and cost specifications show that inflation, even if fully anticipated by all agents, can lead to an increase in aggregate employment; the size of the increase, which varies with the rate of inflation, is, however, quite small. The explanation rests on two factors: changes in the outputs of the price setters, which have been analyzed in the present paper, and the reallocation of consumer expenditure caused by changes in relative prices. Its limitations notwithstanding, the model points to a systematic relationship between anticipated inflation and employment, which in principle can be exploited by policymakers. 


\section{REFERENCES}

Alchian, Armen A., "Information Costs, Pricing, and Resource Unemployment," in E. S. Phelps et al., Microeconomic Foundations of Employment and Inflation Theory (New York: Norton, 1970), pp. 27-52.

Blanchard, Olivier J., "Price Asynchronization and Price Level Inertia," in R. Dornbusch and M. H. Simonsen, eds., Inflation, Debt, and Indexation (Cambridge: MIT Press, 1983), pp. 3-24.

Gordon, Robert J., "Output Fluctuations and Gradual Price Adjustment," Journal of Economic Literature, XIX (1981), 493-530.

Kuran, Timur, "Asymmetric Price Rigidity and Inflationary Bias," American Economic Review, LXXIII (1983), 373-82.

"Anticipated Inflation and Aggregate Employment: The Case of Costly Price Adjustment," Economic Inquiry, XXIV (1986)

Okun, Arthur M., Prices and Quantities: A Macroeconomic Analysis (Washington, D.C.: The Brookings Institution, 1981)

Phelps, Edmund S., and John B. Taylor, "Stabilizing Powers of Monetary Policy under Rational Expectations," Journal of Political Economy, LXXXV (1977), 163-90.

Sheshinski, Eytan, and Yoram Weiss, "Inflation and Costs of Price Adjustment," Review of Economic Studies, XLIV (1977), 287-303. , and - "Demand for Fixed Factors, Inflation and Adjustment Costs," Review of Economic Studies, XLVI (1979), 31-45.

Tucker, Rufus, "The Reasons for Price Rigidity," American Economic Review, XXVII (1938), 41-54. 